\title{
Building Automation and the Contextualization of Information Technology: The Journey of a Midwestern Community College in the U.S.
}

\author{
Neal Grandgenett ${ }^{1}$, Pam Perry ${ }^{2}$, Thomas Pensabene ${ }^{2}$, Karen Wegner $^{2}$, Robert Nirenberg ${ }^{2}$, Phil Pilcher ${ }^{2}$, Candi \\ Otterpohl $^{2}$ \\ ${ }^{1}$ University of Nebraska at Omaha, Omaha, Nebraska, United States of America \\ ${ }^{2}$ Metropolitan Community College, Omaha, Nebraska, United States of America \\ Correspondence: Neal Grandgenett, College of Education, University of Nebraska at Omaha, Omaha, Nebraska, 68182, \\ United States
}

Received: December 28, 2017

Accepted: January 23, $2018 \quad$ Online Published: January 27, 2018

doi:10.11114/jets.v6i2.2959

URL: https://doi.org/10.11114/jets.v6i2.2959

\begin{abstract}
The buildings in which people work, live, and spend their leisure time are increasingly embedded with sophisticated information technology (IT). This article describes the approach of Metropolitan Community College (MCC) in Omaha, Nebraska of the United States to provide an occupational context to some of their IT coursework by organizing IT instruction around the context of building automation systems (BAS). This contextualization allows IT students not only to study IT as a standalone discipline but also to study its integrated use within a specific occupational context. The article also describes MCC's focused curriculum design efforts funded by the National Science Foundation's Advanced Technological Education program. These efforts toward BAS-contextualization of the IT curriculum have become a catalyst for systematic contextualization of IT instruction at MCC and support the institution's broader efforts to become a national model in IT instruction and interdisciplinary engagement within the United States. The research-based approach, activities, and outcomes of this project are all described here, as well as the lessons learned by one community college seeking to make their IT program increasingly relevant to their students and the IT workforce of today.
\end{abstract}

Keywords: information technology, contextualization, community college, building automation systems, critical facilities, internet of things

\section{Introduction}

\subsection{Building Automation Systems}

Walk into many of the modern, new buildings of today, and you may well experience work spaces that are not only visually appealing, comfortable, and optimized for productivity, but you may also glimpse an evolving new field of information technology (IT) — that of building automation systems (BAS). Somewhere typically out of sight from both the visitors and employees, relatively extensive computer and sensor networks are controlling the light and temperature in the room, the soft music in the background, the small waterfall in the lobby, the security monitors in each hallway, the elevators and escalators, the phones and intercoms, the fire-suppression devices, and even perhaps the vending machines in the break room. Welcome to the expanding context of one of the newest job areas for IT specialists-that of building automation technicians. This article describes a case study of one community college, Metropolitan Community College (MCC) in Omaha, Nebraska, as it implemented a project funded by the U.S. National Science Foundation (NSF) Advanced Technological Education (ATE) program to use BAS as a way to "contextualize" IT instruction, grounding such instruction in real-life examples to inform students and get them excited about new career opportunities related to BAS.

\subsection{Local Need for Technicians to Manage Building Automation Systems}

In many ways, IT-based BAS have evolved to address the local, national, and international industry need for integrated management of power, security, communications, and other automated facility systems, and there is now a growing need for technicians who can use BAS to effectively manage such systems (Allied Business Intelligence, 2011). The local need for BAS technicians, as identified by MCC in its Omaha, Nebraska setting, cuts across industry sectors, as one might imagine for this interdisciplinary context. For example, ten Fortune 500 and Fortune 1000 companies have 
their headquarters in Omaha, and they represent various industries, including finance, information technology, manufacturing, construction, and utilities. In addition, the United States Strategic Command, the national command and control center for internationally coordinated strategic forces around the globe, is headquartered in Omaha. The city is also home to several large medical facilities, information-assurance operations, and data centers, with recognized names such as Yahoo!, Google, Verizon, and PayPal. All of these organizations share the need for highly skilled technicians to manage their sophisticated BAS, and the need is rapidly expanding (Allied Business Intelligence Research, 2018). With a vibrant economy and an Omaha Metro population nearing 900,000, the city has seen the steady development of large-scale facilities with integrated, automated control and operations systems. Examples of such facility construction projects that have recently been completed in the city include the following: a $\$ 370$ million cancer research center at the University of Nebraska Medical Center, new headquarters for the U.S. Strategic Air Command and for SAC Federal Credit Union, a \$200 million data center for Fidelity Inc., a Tenaska biofuels trading center, a state-of-the-art technology-enabled Nebraska Crossing retail complex, the Methodist Hospital Surgery Center, and building expansions for Convergys, West Corp, and Offutt Air Force Base-to name just a few.

\subsection{National and International Need for Technicians to Manage Building Automation Systems}

There is also a growing national and international need for BAS technicians. Studies reported that in 2014, the global market for BAS was rapidly growing (Bonino, Corno \& De Russis, 2014) and that as of 2018, buildings now account for approximately $42 \%$ of all electricity use worldwide, surpassing any other IT-related control environment (Allied Business Intelligence Research, 2018). This steady growth reflects an increasing awareness among building owners and operators of the bottom-line impact of integrated, IT-based, and automated building systems for managing energy use, logistics, business analytics, and other important considerations related to both customer service and security (Allied Business Intelligence, 2011).

\subsection{Need for Technician Training}

Given the growing demand for highly qualified BAS technicians, MCC saw an opportunity to use automated building systems as a context for engaging community college students in an integrated and contextualized IT learning environment in which technicians-in-training learned to understand the real-life connections between computers and the environments they control.

In order to examine the regional need for IT-based BAS technician training, MCC surveyed fifteen large companies in the Omaha area (Theis \& Franks, 2012) and interviewed executives with ten more companies to see if such a program might make sense for preparing technicians for potential employment in local organizations. The businesses were relatively diverse and included companies such as TD Ameritrade, CoSentry, First Data Resources, Werner Enterprises, Mutual of Omaha, First National Bank, Alegent/Creighton Hospital System, University of Nebraska Medical Center, ConAgra, West Corporation, Scott Data Technologies, PayPal, the Henry Doorly Zoo and Aquarium, Tenaska Cable Services Group, Oriental Trading Company, University of Nebraska-Omaha, Blue Cross Blue Shield, Northrop Grumman, Data Power, Kiewit, Alvine \& Associates Vanguard, the Omaha Public Schools, and SAC Federal Credit Union. These Omaha-area employers verified that technicians skilled in BAS were increasingly critical for their operations, and $100 \%$ responded that they increasingly required and hired multiple in-house staff to support their automated facilities infrastructure. The majority of respondents indicated that they expected to add record numbers of new and replacement staff by 2020 and anticipated a growing demand for technicians skilled in integrated, automated building systems.

In addition to describing their in-house needs, the employers identified BAS service companies as an important hiring context for BAS technicians. In detailed comments, employers mentioned more than 120 individual Midwestern United States service providers that, as they grow, are struggling to find enough IT specialists skilled in BAS to keep up with demand. For example, Alvine and Associates has evolved from a small electrical and mechanical service provider to a robust international engineering company with specialized divisions in various facets of facilities automation, such as energy management, lighting systems, security, environmental sensing, and telecommunications. This evolving industry landscape reflects, and now appears to be driving, a growing convergence between IT and multiple applied technologies at the core of BAS technician training (Allied Business Intelligence Research, 2018).

The employers surveyed and interviewed also noted the need to upgrade skills of their existing workforce to support facilities operation - a need for which they did not have a ready strategy. Previously, most staffing and training in BAS had occurred through in-house role shifts accompanied by vendor demonstrations and on-the-job training. For instance, several employers reported that their technicians in automated building systems tended to evolve from among existing ranks of electricians or HVAC specialists, rather than emerging from more technical, formal, and IT-oriented BAS training programs. Thus, formal training for building automation specialists has been of particular interest to industry in Omaha. In the survey and interviews, nearly $80 \%$ of the respondents reported that their current technicians do not have 
sufficient formal training in automated building systems, presenting employers and customers with an increased risk for serious system inefficiencies, system failure, and even some potential health hazards. The potential consequences of inefficiencies are serious, impacting the business bottom line across the globe. The impact of system failure can, of course, be even more detrimental, especially for critical industries such as air and rail traffic control, hospitals, data centers, and financial institutions. Over $90 \%$ of Omaha industry respondents indicated full support of additional IT-based BAS training at the community college level, as led by MCC.

\subsection{Existing Programs for Technician Training}

The local demand for formal technician training reflects national trends. Across the U.S., evolving facility technologies have been driving the need for, and the development of, new technician training within what has been called the Internet of Things, where technicians control buildings using the Internet (Schachinger, Fernbach, Wolfgang, 2017). While formal training in automated facility systems has emerged, even the best programs generally emphasize only one or two aspects of building automation, such as energy efficiency or security. Examples of U.S. leaders in this emergent area include the Laney College BEST Center, Georgia Piedmont Technical College's Building Automation Systems training, the Collin College Convergence Technology program, and Oklahoma's Cybersecurity Education Consortium. While these programs provide high quality training, MCC determined that they generally did not reflect the reality of facility operations that require the management of multiple integrated systems, such as heating, ventilation, and air conditioning (HVAC), air quality, lighting, power generation, water, facility security, communications, business analytics, and cybersecurity. These existing model programs also did not appear, at this time, to prepare community college students to manage facility systems that enable customization, such as by programming systems to function differently in specific rooms or areas of a building. MCC believed that the emerging job demands for facility technicians required a stronger educational foundation in IT systems and skills - and that there was a need to integrate IT instruction with BAS training to prepare technicians to manage sophisticated, multi-faceted, automated operations, with control that included monitoring and adjusting BAS systems over the Internet.

\subsection{Need for Contextualization of Information Technology Instruction}

Incorporating a foundation of IT systems and skills in BAS technician training in many ways requires an overall redesign of IT instruction. Within the U.S., IT skills are still largely taught through IT department silos, void of sector and occupational context, despite the fact that the vast majority of technology students apply their skills in occupations NOT classified as IT jobs (Carnavale, 2013). While progress has been made in contextualizing specific IT skill-building activities through traditional means, such as scenario-based learning, capstone projects, and internships, the vast majority of IT instruction across the nation is built upon relatively abstract exercises disconnected from an occupational context. Technology skills are also typically taught in isolated units—programming, web security, controls—rather than presented and practiced together as components of real, integrated, and interdependent systems.

As a result of the insufficient integration and balance of IT and Applied Technology content in current training programs, technicians in Omaha and other U.S. cities enter the workforce with mechanical know-how, but generally without a thorough understanding of IT-based systems. This hampers their efforts to isolate problems, strategically troubleshoot, proactively manage technology-enabled industry systems, and prevent system inefficiencies and breakdowns. Industry partners report that employees' lack of understanding of technology-based systems leads them to employ a high-risk trial-and-error or "band-aid approach" to resolving problems in automated facilities systems. Without an IT-based systems understanding, a "fix" in one area often spurs a new problem elsewhere within the software or hardware components.

Contextualization, which is typically identified as growing out of problem-based learning (Bond, 2004), is often critical for preparing students to effectively use the knowledge and skills learned within a curriculum. Educational research has long demonstrated that students have difficulty transferring and applying non-contextualized skills to real-life situations (Perkins \& Salomon, 1989; Perin, 2011). Training that is void of context and integrated content often results in a "swiss cheese" effect, wherein students fail to acquire broader, foundational understandings of systems and underlying theory and lack a working knowledge of the relationships of components within a system. Without a strong foundation of mastery and meaning in occupational training, individuals are limited in their abilities to engage in efficient, systems-level problem solving and the continuous learning necessary to advance their workplace skills (Son \& Goldstone, 2009; Kalchik \& Oertle, 2010). Instruction that is contextualized to focused applications, sectors, and occupations results in stronger learning and workplace outcomes, increasing student skill mastery, retention, transfer, and problem solving (National Council for Workforce Education \& Jobs for the Future, 2010; Bond, 2004). Contextualizing IT training is also important for student recruitment. Particularly among women, contextualized training supports student recruitment and retention, increasing the perceived relevance of training to job attainment (Flannery, 2000).

\subsection{Developing a Contextualized IT Training Program for Building Automation Technicians}

Based on industry guidance, a review of existing technician training programs, and educational research related to 
contextualizing IT instruction, MCC determined there was a clear need to provide instructional programming that integrated IT education with BAS technician training. It was determined that the competency model for BAS training must align with an evolving industry, increasing the focus on IT skills and integrated systems management. To prepare students to manage, problem solve, and continuously learn and adopt new automated facility systems, the new program must provide a strong foundation in technology-based systems and skills. BAS training needed to be presented to students in a contextualized, technology-rich curriculum that leads to active, technology-enabled careers in advanced, automated facilities systems. Such an approach, if it could be successfully operationalized by MCC, would serve to build a diverse pipeline of capable technicians who possess the skills needed in the growing and challenging field of building automation.

To support its efforts to develop, refine, and ramp up a new IT-oriented BAS curriculum, MCC proposed a grant project to the NSF ATE program. The project, called Automate, was awarded NSF funding for three years (NSF \#1400557). Work was initiated on August 1, 2013 and completed in December of 2017. The new program is now fully sustained by MCC.

\section{Methods}

The Automate project for BAS technician training at MCC addressed two of NSF's key ATE focus areas at the time-CCurriculum and Educational Materials Development" and "Professional Development for Educators." The project's overall goal was "to develop, field test, and deliver learning resources for contextualized IT technician training," and this goal was operationalized through the following three project objectives:

1. Develop, pilot, refine, and provide accessible educational resources for effective outreach and instruction in the new model of BAS-contextualized IT education,

2. Increase faculty capacity for BAS-contextualized IT instruction, and

3. Sustain, disseminate, and support the adoption of BAS-contextualized IT technician training models and resources.

\subsection{Strategies for Developing Educational Resources}

Upon receipt of the NSF funding, the Automate investigators began work on the three objectives. For the first objective related to developing educational resources, the investigators assembled a small project planning team that included an internal Subject Matter Expert (SME)—MCC's multi-campus Energy Systems Management Coordinator. Initially, industry engagement was informal, with business partners typically providing input through one-on-one communications. These relationships were quickly formalized into the Automate Business and Industry Leadership Team (BILT) composed of business partners who participated in a Developing a Curriculum (DACUM) process (Adams, Hogan, Steinke, 2015) focused on analyzing the occupational competencies required of building automation technicians. Following initial analysis, BILT representatives supported the development of new educational resources through contributions such as completing surveys on BAS technician skills, serving as adjunct faculty, assisting the SME, developing a module for system optimization, providing access to active BAS for the recording of instructional videos, and participating in interviews for videos that were incorporated into curriculum activities.

Automate partners also developed and implemented a plan for year-round BAS outreach and early college experiences. Outreach planning began by engaging MCC graphic design students in the development of an Automate brand and marketing plan. The MCC students designed a logo, flyers, banners, website presence, and external graphics for the Automate mobile training unit. These student-designed products were showcased at the yearly NSF ATE conferences and were used extensively for Automate outreach efforts. MCC also piloted six different BAS outreach workshops for high school students, ranging in length from one hour to one day. Workshop topics included networking, programming, graphical and human interfaces, and system optimization. These workshop topics and activities were also incorporated into BAS-contextualized IT courses. The workshop modules also served as foundational elements of dual credit summer academies for high school students.

BAS-contextualized IT courses were systematically built upon the DACUM profile that specified the competencies necessary for effectiveness in the role of a BAS technician. One noteworthy outcome of the BAS technician profiling was the very high number of technology competencies identified as being required of BAS technicians. This validated the Automate approach to preparing BAS technicians through an IT-based degree program.

An additional Automate resource, completed in 2016, was the mobile BAS learning lab, similar to the mobile education unit in use through Northeast Wisconsin Technical College. As mentioned, the mobile unit was wrapped with eye-catching graphics designed by MCC students and outfitted with numerous BAS activities. Technologies purchased for the mobile training unit were used for the majority of more than thirty workshops completed across the city as of 2017, and the training unit continues to be used to showcase the new BAS training program.

\subsection{Strategies for Increasing Faculty Capacity}

To build overall faculty capacity for BAS-contextualized IT instruction, the Automate team initially planned to host 
annual summer workshops led by the project SME. Following initial work with faculty, it was apparent that the better approach would be to develop a smaller number of faculty "champions" or early adopters who could then serve as models and promoters of BAS-contextualized IT instruction. To reach this end, the project SME and instructional designer worked very closely with a select subset of faculty, developing plans for contextualizing existing IT courses. These plans also included some co-teaching between the SME and IT faculty. This approach provided strong examples of best practices that could then be shared through annual faculty workshops and additional teaming on BAS-contextualized IT course development.

Initial activities with faculty also pointed out the need to strengthen faculty members' approach to competency-based education (CBE), which has a long history of success in technical education at community colleges (Jones, Olswang, 2017). The BILT's DACUM profile called for CBE, with very specific expectations for demonstrable skill outcomes. To meet industry expectations for instruction, learning, and competency-based assessment, it was apparent that faculty could benefit from CBE tools and training. To meet this need, MCC acquired the Worldwide Instructional Design System (WIDS) electronic tool for curriculum development, which was supported through various faculty trainings.

During the NSF-funded efforts, the project team created numerous instructional resources, particularly related to flipped classroom environments, including supporting videos for both students and faculty. The videos for students are used to help students learn or to reinforce concepts such as Boolean Logic and systems operation. Videos for faculty were created to facilitate and support faculty efforts to integrate contextualized learning in disciplines where they do not have extensive experience or expertise. Most of the videos were from 2 to 4 minutes long and were fully captioned. A longer video of 20 minutes introduced key concepts about BAS. Eventually, these videos were uploaded to YouTube for use by other educational institutions worldwide.

MCC, area public school districts, and several of the business-partner faculty participated directly in the BAS-contextualized IT pilots through department meetings, MCC public relations releases, course pilots, Midwest Center for Information Technology (MCIT) partner communications, and informal networks. Faculty members participating in Automate pilots were supported by an initial training process, with both individual and group sessions and face-to-face or remote coaching by the project's principal investigator, key personnel, and experienced MCC faculty. Self-study guides were created in the WIDS instructional design system and have been used extensively for faculty training and preparation, both for early faculty adopters and as support for later faculty adopters. The Automate team also presented sessions at Working Connections conferences (a regional conference for community colleges) to reinforce faculty capacity for BAS-contextualized IT instruction in a wider four-state area in the Midwest. Participating faculty co-presented extended sessions at the yearly Working Connections conferences (2015, 2016 and 2017), furthering their depth of knowledge, skill, and leadership in providing and promoting contextualized IT education.

\subsection{Strategies for Further Building Partnerships and Sustaining the Project}

Any new educational program that is initially established with grant funding needs to consider sustainability after the grant ends, and this was true of the Automate project. Activities to promote long-term sustainability, dissemination, and institutional support were initiated early and ramped up well, including participation in regional and national conferences and development of a project website and blog. A project overview video was also developed, which was shared through the Automate website and through presentations at national High Impact Technology Exchange (HI-TEC) conferences, where numerous community colleges were working on various IT contextualization efforts.

Another key to sustainability and dissemination, partly encouraged by the success of Automate, is MCC's new 2017 Center for Advanced and Emerging Technology (CAET), which was built upon the Automate BAS-contextualized IT technician-training model. This building houses programs associated with BAS, critical facilities management, building maintenance, and technology and transportation and also includes an academic data center, simulation labs, a fabrication lab, exhibition spaces, business incubator spaces, economic development offices, teleconferencing space, and various team and individual work spaces. The CAET will help with long-term sustainability of BAS-contextualized IT educational resources and professional development and will support plans for new programs of IT contextualization developed around the Automate model. For example, the CAET resources have already been used to support development of two new lab-based workshops and four new video-enhanced, scenario-based IT learning modules.

From the start, Automate worked closely with the BEST Center (an NSF Regional IT Center) to share ideas about contextualizing IT related to BAS. Dissemination and further partnership building was also promoted through MCC's role as a leadership school in the National Coalition of Certification Centers (NC3). Finally, as BAS instructional resources were developed, they continued to be provided through open online portals such as YouTube, with links to key peer and professional sites.

As the Automate program grew steadily toward sustainability, the program's instructional designer also worked closely with the MCC Critical Facilities (CF) instructional program to integrate BAS. In 2016, the college moved forward with 
an integrated CF and BAS Associates of Arts degree, which was approved by Nebraska's Coordinating Commission for Postsecondary Education, a necessary and final step for degree offerings in Nebraska. In addition, an Understanding by Design (UBD) template was created and piloted with two instructors to help bridge gaps in understanding among faculty with differing backgrounds in IT, BAS, and Critical Facilities. The Automate instructional designer helped to lead the UBD discussions.

\section{Results}

Several deliverables related to BAS-contextualized IT education have been achieved within the Automate project. The project continues to refine these results and deliverables, and the program documentation is available free of charge to other institutions who might be interested in replicating this contextualization process in their own IT programs. These program deliverables include the following.

\subsection{Occupational Profiles and Logic Model}

Early in the Automate project, eight MCC staff and faculty participated in an initial DACUM training, and they now lead industry panels in the development of occupational profiles and related curriculum maps. In addition to the original DACUM profile completed for the Automate project, new DACUM profiles have been developed and are available on the project website. Informed by the Automate project and the need to further strengthen the integration of IT and "trades" content in technician training, MCC reconvened the Automate BILT and updated the occupational profile and curriculum map for the overall Critical Facilities degree, which now contains the BAS contextualization. In addition, MCC convened a Data Center BILT and updated the occupational profile and curriculum map for the Data Center degree. As mentioned, a new state-of-the-art academic data center was recently built (as part of the new CAET building) to host the IT program, including the Data Center technician training. Many of the ideas for the new center evolved from thoughts initially relayed in the DACUM profile. Furthermore, MCC was one of two community projects selected by the ATE program to pilot a new approach for logic modeling, and the refined Automate project logic model is available from the Automate website.

\subsection{Feedback Surveys and Focus Group Protocols}

Automate staff and instructors routinely give surveys to students and workshop participants to solicit feedback after each course and workshop. These surveys were validated for the project and derived from previous NSF projects associated with members of the Automate team (Grandgenett, Thiele, Pensabene, McPeak, 2015; Grandgenett, Ostler, Topp, Goeman, 2012). Each feedback survey has ten or more questions associated with formative input. Students and participants surveyed frequently indicated a high level of agreement on questions asking about their perceptions of the benefits of the Automate intervention and whether they would recommend the intervention to other future students/participants (with means of 4.8 or higher on a 5.0 Likert scale). Sample surveys and template formats for displaying the summary results are available to interested institutions on the project website. Further, faculty and student focus group protocols were developed, implemented, and refined, leading to project enhancements. Those protocols and sample results templates are also available on the project website.

\subsection{WIDS Curriculum Development Tool}

As mentioned in subsection 2.2, Automate staff/faculty members were trained to use WIDS, an electronic tool for designing and developing curriculum. The tool supports the alignment of competency outcomes, course objectives, and industry standards, while enabling creativity and diversity as faculty design specific instructional activities. WIDS is now used to support the development of all new IT programs and courses at the college after the success of using it in Automate. The instructional designer for Automate is now a frequent national contact for WIDS-related discussions and advice. In addition, supplementary supports for faculty who are learning and implementing WIDS as a tool for curriculum design were also developed in the project.

\subsection{Augmented Reality Learning Tool}

A smartphone-based augmented reality (AR) resource was developed by the project instructional designer, enabling workshop participants to look at components of the BAS hardware with an annotated visual overlay that recognizes and identifies the components when using them in an instructional setting. The AR efforts used a software application called Aurasma that was particularly compatible with smartphones and could be downloaded by students working with BAS hardware. This was one of the very first AR uses at MCC, and other programs are now looking at using AR in their technical instruction, such as in automotive and truck repair technician tracks.

\subsection{Conference Showcases}

MCC developed and steadily enhanced booth displays for various national conferences where the Automate team presented and networked with other community colleges. These conferences included the national HI-TEC conference 
as well as the ATE national conference. Each showcase received strong interest and very positive feedback from other conference participants, and the showcase strategies, backdrops, and innovative display of working BAS prototypes are shareable with interested community colleges. Further, the Automate SME has also provided a presentation on the BAS-contextualized IT workshops that included demonstrations of the industry-grade hardware kit ("BridgeIT") and industry software for block-based programming and automated control of heating/cooling systems. Several support videos associated with the ATE presentations are available. Figure 1 shows an inexpensive cardboard box model "BoxIT" instructional resource showcased at the conference and used within the curriculum for student engagement.

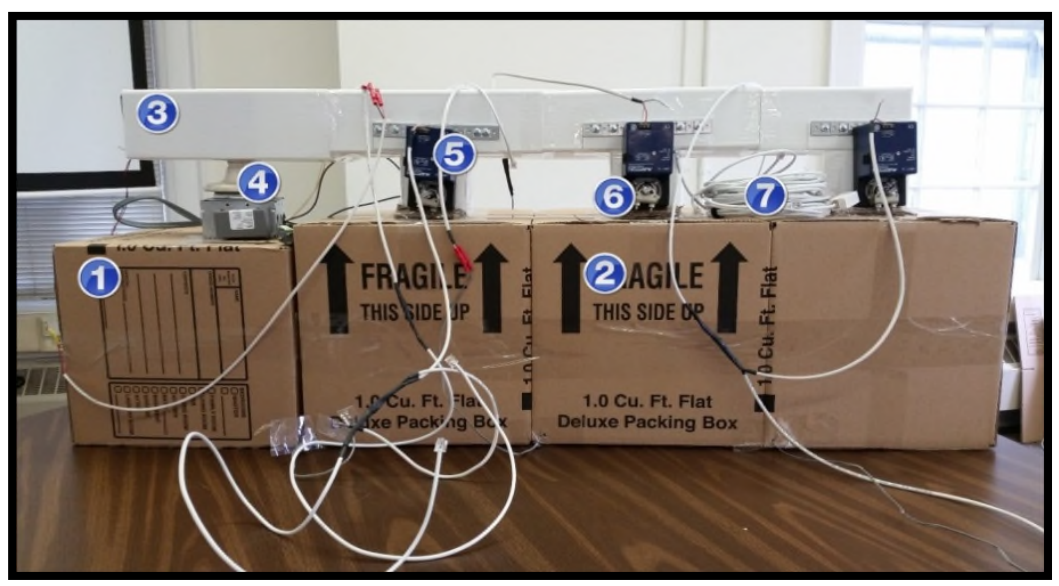

Figure 1. Sample BoxIT building automation system cardboard box model

Figure 1 represents a training activity that uses cardboard boxes and inexpensive electronic components to show how a BAS system in a strip mall would work. The items include: 1) support for heat source, 2) boxes representing strip mall shop spaces, 3) HVAC ductwork (fan inside ductwork not visible in image), 4) heat source (light bulb), 5) damper anti-rotation bracket, 6) damper actuator (air control mechanism), and 7) wire harness with temperature sensor and six conductor wires to connect to control panel.

\subsection{Lab Trainers}

Lab training units were also developed in Automate for supporting project-based, BAS-contextualized IT training. These mini-units have been used in numerous workshops and courses since the summer of 2015 for various train-the-trainer sessions. They were further redesigned during the Fall semester of 2016 to be more accessible and more affordable, incorporating Raspberry Pi computer technologies as an option rather than industry grade technology. Figure 2 shows a lab trainer.

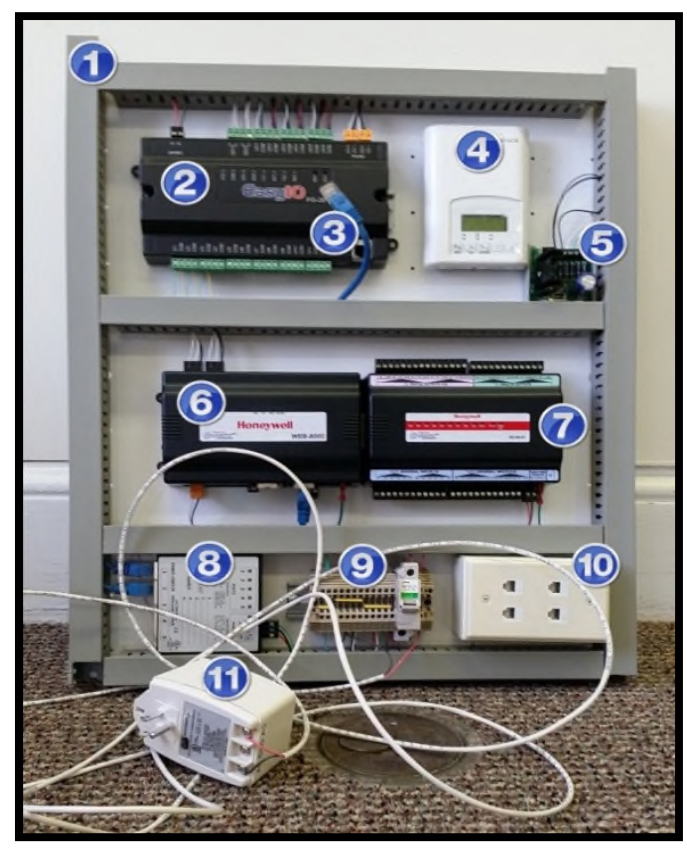

Figure 2. BridgeIT Lab trainer using actual building automation system panel 
Figure 2 represents a basic building automation system that might be programmed in classes. The items include: 1) panel frame, 2) easy input/output (IO) controller, 3) Ethernet connection, 4) smart thermostat; 5) AC/DC power supply, 6) Honeywell Web 600, 7) IO 34 input/output, 8) network switch, 9) electrical terminations and breaker on/off switch, 10) terminators from jumper wires, and 11) power supply.

\subsection{Student Designed Outreach Resources}

As mentioned earlier, MCC graphic design students developed an Automate outreach plan and branding, including vertical and horizontal banners, flyers, a logo, website graphics, and an outside "wrap" for the mobile learning lab, which is a truck trailer. The information and sample images of the student work have been shared with other graphic design classes in the area, and the students in the MCC design classes regularly enhance the various design elements.

\subsection{Mobile Learning Lab}

While not funded through NSF, a mobile lab to take Automate displays and instruction to local sites was also purchased from leveraged funding and branded to support Automate outreach workshops. This large truck trailer was used to support various off-site trainings and student recruitment efforts. The trailer is now frequently requested by area high schools and the community at large for events such as college and job fairs.

\subsection{Evaluation Plan and Institutional Review Board Approval}

It is important to note that many external funders, such as NSF, require an evaluation plan that is also approved by a formal Institutional Review Board (IRB) for the protection of human subjects. The Automate project developed an extensive evaluation plan, that includes an IRB approval letter from the University of Nebraska Medical Center IRB. Although seeking IRB approval takes time, it is typically important in today's student-data environment, and any program (even if internally funded) that plans to publish its results should consider obtaining IRB approval. The formal IRB approval process helps a project or college to demonstrate that it has established procedures to ensure the privacy and security of student data and to adequately address other important considerations relevant to the safety and wellbeing of project participants.

\subsection{Automate Workshops}

The project developed and delivered numerous Automate workshops focused on BAS-contextualized IT training in areas such as networking and programming. These workshops included various videos and graphics developed for use in the workshops with students and/or as learning resources for workshop facilitators. In addition, hardware ("BridgeIT") and building materials ("BoxIT") instructional kits were designed for workshops and courses, as displayed in Figures 1 and 2 (see subsections 3.5 and 3.6).

\subsection{IT/BAS Videos}

Short YouTube videos of 10 minutes or less were developed to introduce students to IT/BAS careers. In addition, workshop participants provided feedback on their experiences in Automate workshops that were often used to refine the instructional processes and steps shown in the program videos and to incorporate participant testimonials. These videos were also used for outreach and participant recruitment. Selected videos were further used at conferences and wider public events to explain the coursework and program.

\subsection{BAS-Contextualized Introduction to IT Courses}

Two BAS-contextualized IT courses were designed and are now fully integrated across the MCC IT coursework, including one in a hybrid format and one in a project-based format. While a full time IT faculty member leads the hybrid course, the Automate SME teaches the project-based version (as an IT adjunct faculty member). The project-based class has steadily evolved into a model course at MCC, which has already been shared with other institutions across the United States.

\subsection{BAS Working Connections Conference Train-the-Trainer Sessions}

The project team created a two-day train-the-trainer model workshop session, which is now routinely presented at conferences, such as at the Working Connections regional conference for community colleges (every June in Council Bluffs, Iowa). The workshop leaders train individuals on BAS-contextualized, project-based, hands-on IT instruction, and participants walk away with the instructional resources to replicate the training. Participants also have long-term access to the Automate project team for implementation support. These same train-the-trainer materials are available as project materials from the website and are now often shared with various other community colleges.

\section{Discussion}

In just a few short years, the Automate team, supported by the overall ATE program and colleagues, made significant progress in contextualizing IT instruction at MCC. Being funded by NSF, with the corresponding expectations for 
excellence and results on a short timeline, demanded a lot of the team, but it also helped them to pull together and encouraged the college's administration to get behind the project. In reflecting on the program's development and implementation, the team identified a few "lessons learned" to share with others attempting large-scale educational innovations at community colleges. These lessons include strategies for effectively managing externally funded educational reform projects as well as lessons related to contextualizing IT instruction.

\subsection{Don't Be Afraid to Take Strategic Risks}

NSF funding, by design, includes requirements for "intellectual merit" and "broader impacts." Such requirements demand some risk taking. In general, assume that it is okay to be wrong, as long as you 1) learn from your mistakes and 2) share what you learn. This risk-taking mindset is not always easy for educators or business professionals to maintain, so the Automate leadership team had to constantly remind all team members and partners that it was okay to take risks and that it was fine if some project efforts did not go according to plan, as long as the project team continued to "course correct" to make the next iteration more successful. The NSF program officer and ATE colleagues frequently helped the team consider possible refinements to the original plan. In addition, the Automate team members worked consistently with the external evaluator, using information gleaned from surveys and focus groups and drawing on the evaluator's external perspective to help the team self-correct in its efforts to continuously improve the project.

\subsection{Set Realistic Objectives from the Beginning}

The Automate team had to take small initial steps, such as focusing directly on assembling an effective advisory team, rather than jumping right into curriculum development. That was hard at first, since the team wanted to move quickly given the aggressive NSF timeline. The team also had to scale back some of the initial outreach efforts to high schools until more of the college curriculum was in place. The Automate team found that it could easily get overwhelmed by outreach and student recruitment activities before the program was well enough established for students to enroll in the program at the college. That said, the team also hit the ground running and maintained a steady pace, with the leadership team routinely deciding what steps could be done simultaneously. A fast, careful start on realistic initial objectives is important to keep everyone on the same page and to ensure steady progress.

\subsection{Maintain a Regular Meeting Schedule to Prevent Mission Creep}

In a complex effort involving a large interdisciplinary team, it is important to meet regularly to help team members stay focused on achieving anticipated deliverables. For Automate, the project team found that monthly meetings worked the best for processing tasks, making decisions, communicating, and generally keeping the project on track. Regular meetings helped the team avoid the common mistake of beginning to undertake something that was not directly related to the grant deliverables or that did little to contribute to the overall project, even though it seemed worthy in a more general sense. The team often revisited the stated objectives of the proposal and the MCC organizational mission as the project progressed.

\subsection{Keep Intellectual Merit and Broader Impacts in Mind}

In NSF grants, as mentioned in 4.1, there are two key components-intellectual merit and broader impacts. Intellectual merit is related to how the project is building the knowledge base, and broader impacts are ways in which the project can benefit society. For Automate, intellectual merit revolved around the curriculum itself and strategies for contextualizing IT using BAS. Broader impacts related to how the Automate project was creating new pathways for high school students to enter IT and STEM careers. By revisiting those two ideas and consistently conveying them to faculty, partners, and students, the leadership team kept the overall focus on achieving the desired learning differences that had been promised to NSF. The team also found that a good external evaluator was critical for keeping the project on track.

\subsection{Engage an Instructional Designer}

For large-scale curriculum innovations, it is important to engage someone with expertise in instructional design. That is especially true in today's world of online and blended learning, where the curriculum materials are increasingly important for guiding instruction. The Automate project engaged a very experienced instructional designer, who provided significant help in translating the content and activities conceptualized by the SME into effective learning experiences for students.

\subsection{Provide Professional Development Training, Resources, and Support}

The very concept of providing an occupational context for IT instruction demands that instructors "get out of their comfort zone." In the case of Automate, traditional IT instructors often had little or no experience with BAS or the Internet of Things context where the electronics and programming worlds come together. In order to contextualize their IT instruction, these faculty required considerable professional development and ongoing access to the SME. 
Professional development was also required for some staff members. In addition, the project team needed to acknowledge and prepare others for the fact that contextualization and interdisciplinary work are indeed difficult, but, in the long term, are worth the effort, particularly for bringing in new students and effectively preparing them for new career paths in IT and BAS.

\subsection{Maintain Enthusiasm to Win Over Doubters}

In every educational reform effort, there are faculty, administrators, partners, and others who do not necessarily share the leadership team's vision and will not participate fully or agree to change their own practices. The Automate project encountered such doubters periodically, and the team found that if they were polite and enthusiastic in their leadership efforts, the reform process eventually won over faculty who were reluctant to either participate in the project or to accept its contextualized curriculum as a viable pathway for the college's students to learn IT.

\subsection{Develop Active-Learning "Trainer Kits"}

To effectively contextualize IT instruction in BAS, instructors needed to be able to illustrate how various technological components work together in automated building systems. To meet this need, the project team's SME created inexpensive kits out of electronic components and cardboard boxes. The kits were designed to be assembled and unassembled quickly and included detailed directions on how to control the electronic components over the Internet. These "trainer kits" went a long way toward building an effective learning experience for both the MCC students and Automate workshop participants.

\subsection{Keep an Eye on IT from an Industry Perspective}

Throughout the project, it was important for the Automate team to consider how new IT knowledge and skills connected to industry careers and needs, rather than just focusing on the inherent fun or interest of the IT. For example, although it was relatively easy and interesting to learn to control things like electronic music, the team found that learning to control things like fans, lights, pumps, and other physical components of BAS was worth the extra effort, as these components are more important in the typical occupational contexts in which such IT skills and knowledge would be applied.

\section{Final Comments}

Finally, as efforts to contextualize IT instruction at MCC continue, the Automate project team has come to realize that such contextualization serves many purposes. For example, it helps students see that IT is in everything, and it opens their eyes to a world of possibilities. Furthermore, the process clearly grounds a student's IT preparation in a particular career interest area. These advantages are indeed powerful, for both the students at a particular college and the world community of students, as the nation's community colleges seek to increase the STEM workforce to meet growing local, national, and international demand for IT specialists in diverse occupational contexts.

It is also apparent from the Automate project experience that developing models for contextualizing IT instruction and undertaking interdisciplinary program design, development, and delivery is not easy—but it is doable and worth the effort. Such educational innovation demands a team of committed faculty and staff that work collectively and systematically toward contextualization. It relies on expertise that is truly distributed, and it certainly helps to break down institutional silos. It demands avenues for self-assessment and continuous improvement as well as steady project evolution. Most importantly, it is necessary to have a strong team with multiple, well-defined roles and perspectives, and it is especially important to support those who are teaching in an IT contextualization instructional environment. Division of labor is critical on these types of interdisciplinary curriculum efforts, and this was indeed the case for the MCC institutional educational reform process associated with Automate.

At MCC, the Automate project has become a springboard for expanding the college's IT curriculum around the "Internet of Things," and such a context is becoming an ever stronger reality for IT education at MCC, as it is for many community colleges today. Whether in facilities, appliances, vehicles, smartphones, or the many other components that humans control and are controlled by in life, the Internet is there and is becoming ever more ubiquitous. Whether humans control technology or technology controls humans may be to some degree the responsibility of educators and educational institutions, who can help students to become career professionals with the skills to be effectively in charge of the technology. At MCC, and among the Automate team, it is a core belief that students deserve to learn IT in a context of control, as well as one of potential, not only for them, but for the society at large.

\section{Acknowledgements}

The authors would like to acknowledge the three years of funding and support from the National Science Foundation's Advanced Technical Education program, which funded the Automate Project as Project \#DUE 1400557. 


\section{References}

Adams, R. E., Hogan, R. L., \& Steinke, L. J. (2015). DACUM: The seminal book. Wilmington, DE: Edwin \& Associates.

Allied Business Intelligence (2011). Commercial Building Management Systems Research Report, 1-67. Retrieved July 7 , 2012, from http://www.abiresearch.com/research/Product/1006311-commercial-building-management-systems.

Allied Business Intelligence Research (2018). Commercial Building Management Systems: Energy Management, HVAC, Lighting Controls. Retrieved January 10, 2018, from

https://www.abiresearch.com/market-research/product/1006311-commercial-building-management-systems/.

Bond, L. P. (2004, January). Using contextual instruction to make abstract learning concrete. Techniques: Connecting Education and Careers, 79(1), 30-33.

Bonino, D., Corno, F., \& De Russis, L. (2014). A semantics-rich information technology architecture for smart buildings. Buildings, 4(4), 880-910. https://doi.org/10.3390/buildings4040880

Carnavale, A. (2013). Hard Times: College Majors, Unemployment, and Earnings. Georgetown Public Policy Institute, Center on Education and the Workforce. 1-17. Retrieved August 10,2013: http://www9.georgetown.edu/grad/gppi/hpi/cew/pdfs/HardTimes.2013.2.pdf.

Grandgenett, N. F., Ostler, C., Topp, N., \& Goeman, R. (2012). Robotics and problem-based learning in STEM formal educational environments. In B. Barker, G. Nugent, N. F. Grandgenett, \& S. Adamchuk (Eds.), Robots in K-12 education: A new technology for learning (pp. 94-119). Hershey PA: IGI Global. https://doi.org/10.4018/978-1-4666-0182-6.ch005

Grandgenett, N. F., Thiele, L., Pensabene, T., \& McPeak, B. (2015). It takes a village to raise an IT project: Suggestions on collaboration from our 10-community-college consortium. Community College Journal of Research and Practice, 39(7), 647-658. https://doi.org/10.1080/10668926.2014.883555

Hayes, E., \& Flannery, D. D. (2000). Women as learners: The significance of gender in adult learning. San Francisco, CA: Jossey-Bass.

Jones, K. A., \& Olswang, S. G. (2017). Building competence: A historical perspective of competency-based education. In K. Rasmussen, P. Northrup, \& R. Colson (Eds.), Handbook of research on competency-based education in university settings (pp. 28-40). Hershey, PA: IGI Global. https://doi.org/10.4018/978-1-5225-0932-5.ch002

Kalchik, S., \& Oertle, K. M. (2010). The theory and application of contextualized teaching and learning in relation to programs of study and career pathways. Transition Highlights Issue No. 2, 1-6. Retrieved August 10, 2012, from http://files.eric.ed.gov/fulltext/ED513404.pdf

National Council for Workforce Education \& Jobs for the Future (2010). Breaking through: Contextualization toolkit. Retrieved December 10, 2017, from http://www.jff.org/initiatives/back-track-designs.

Perin, D. (2011). Facilitating student learning through contextualization. CCRC Working Paper No. 29. Retrieved July 10, 2013, from https://doi.org/10.1177/0091552111416227

Perkins, D. N., \& Salomon, G. (1989). Are cognitive skills context-bound? Educational Researcher, 18(1), 16-25. https://doi.org/10.3102/0013189X018001016

Schachinger, D., Fernbach, A., \& Kastner, W. (2017). Modeling framework for IoT integration of building automation systems. at - Automatisierungstechnik, 65(9), pp. 630-640. https://doi.org/10.1515/auto-2017-0014

Son, J. Y., \& Goldstone, R. L. (2009). Contextualization in perspective. Cognition \&Instruction, 27(1), 51-89. https://doi.org/10.1080/07370000802584539

Theis, P., \& Franks, T. (2012). Building Automation Systems Industry Survey. Unpublished raw data. Information available from Wipro, Omaha, NE: Paul.Thies@wipro.com.

Thompson, T., Heer, D., Brown, S., Traylor, R., \& Fiez, T. S. (2004). Educational design, evaluation and development of platforms for learning. In Proceedings of the Frontiers in Education 34th Annual Conference, Savannah, Georgia, October 2004, (1), T3E/1-T3E/4. https://doi.org/10.1109/FIE.2004.1408531

\section{Copyrights}

Copyright for this article is retained by the author(s), with first publication rights granted to the journal.

This is an open-access article distributed under the terms and conditions of the Creative Commons Attribution license which permits unrestricted use, distribution, and reproduction in any medium, provided the original work is properly cited. 